\title{
Recent Cycle Time Reduction at Langley Research Center Jerome T. Kegelman*
}

\author{
NASA Langley Research Center, Hampton, Virginia
}

\begin{abstract}
$\underline{\text { ABSTRACT }}$
The NASA Langley Research Center (LaRC) has been engaged in an effort to reduce wind tunnel test cycle time in support of Agency goals and to satisfy the wind tunnel testing needs of the commercial and military aerospace communities. LaRC has established the Wind Tunnel Enterprise (WTE), with goals of reducing wind tunnel test cycle time by an order of magnitude by 2002, and by two orders of magnitude by 2010 . The WTE also plans to meet customer expectations for schedule integrity, as well as data accuracy and quality assurance. The WTE has made progress towards these goals over the last year with a focused effort on technological developments balanced by attention to process improvements.

This paper presents a summary of several of the WTE activities over the last year that are related to test cycle time reductions at the Center. Reducing wind tunnel test cycle time, defined here as the time between the freezing of loft lines and delivery of test data, requires that the relationship between high productivity and data quality assurance be considered. The efforts have focused on all of the drivers for test cycle time reduction, including process centered improvements, facility upgrades, technological improvements to enhance facility readiness and productivity, as well as advanced measurement techniques. The application of internet tools and computer modeling of facilities to allow a virtual presence of the customer team is also presented.
\end{abstract}

\section{$\underline{\text { ABBREVIATIONS }}$}

AOA Angle of Attack

CFD Computational Fluid Dynamics

CPM Critical Path Management

ISO International Standards Organization

LaRC Langley Research Center

MEMS Microelectromechanical Systems

* Head, Research Facilities Branch, Aero- and Gas-Dynamics Division, Member AIAA.

Copyright (C) 1999 by the American Institute of Aeronautics and Astronautics, Inc. No copyright is asserted in the United States under Title 17, U.S. Code. The U.S. Government has a royaltyfree license to exercise all rights under the copyright claimed herein for governmental purposes. All other rights are reserved by the copyright owner

\author{
MDOE Modern Design of Experiments \\ NIST National Institute of Standards and \\ Technology \\ NTF National Transonic Facility \\ PMI Projection Moiré Interferometry \\ PSP Pressure Sensitive Paint \\ TPMS Test Plan Management System \\ TSP Temperature Sensitive Paint \\ SQC Statistical Quality Control \\ UPWT Unitary Plan Wind Tunnel \\ VMD Video Model Deformation \\ WTE Wind Tunnel Enterprise
}

\section{INTRODUCTION}

It has been well established that wind tunnel testing amounts to a significant portion of the development cycle of any aeronautical vehicle. Also, aircraft design decisions are made on ever finer variations in experimental results, requiring more accuracy out of each test. It is expected that the demand for shorter testing cycles and increasing data precision requirements will continue in the future.

In 1995, LaRC established metrics (References 1-2) that focused on the goals of increasing productivity, increasing customer satisfaction, and reducing cost. Reference 3 gives some insight into how our thinking in these areas has changed over the last several years. The major wind tunnel facilities at LaRC have been conducting continuous improvements for several years now and diligently measuring progress by tracking cost per polar, polars per hour, and customer satisfaction. Work has been focused on reducing the cost of testing and on increasing productivity. The cost per data point has dropped by a factor of two, and the number of data points per year has increased by a factor of three. Unfortunately, the average cost per test has increased by a factor of 30 percent, because very few customers are willing to leave a facility before the end of the scheduled test entry, opting to stay and obtain second and third level priority data instead. Furthermore, while customer satisfaction has steadily increased, an opportunity for improvement on many customer surveys is that the scheduled test entry is too far into the future. With this enormous increase in productivity, about the same number of tests per year were being conducted in each facility, and the customers still waited for 1-2 years to get into a 
facility. This paper will discuss a few of the efforts undertaken at $\mathrm{LaRC}$ in 1998 that address these issues.

The Langley WTE strategy for meeting the customer demands for shorter production cycles and much finer experimental data in the future has been stated in the Langley WTE Goals listed in Reference 3. These goals were developed in 1997 to address the dichotomy that the tunnels at LaRC have for several years increased productivity based on data volume, yet the total number of tests per year and the test cycle time was remaining constant. The set of WTE goals that are related to wind tunnel test cycle time are:

By 2002 the WTE will provide:

World class subsonic, transonic, and supersonic test capability in support of NASA's goals for Global Civil Aviation, Access to Space, and Revolutionary Technology Leaps

Fast, low cost, concept screening test capability across the Mach range $(0<M<20)$ to support the development of the next generation commercial and military aircraft and space launch vehicles

The WTE fully integrates advanced wind tunnel testing into the next generation aircraft design processes by providing:

An order of magnitude reduction in complete wind tunnel test cycle time by 2002 and two orders of magnitude reduction by 2010

Virtual participation by test team for entire test cycle

The WTE meets all commitments to programs and customers' expectations in a timely manner while maintaining technical and operational excellence through continuous improvement of ISO 9001 certified processes in the areas of

- $\quad$ state of the art test techniques

- efficient test processes

- $\quad$ reliability centered maintenance

- value added attitude

\section{QUALITY ASSURANCE AND PRODUCTIVITY}

Over the last decade, the requirement for accuracy in wind tunnel testing has changed by an order of magnitude. For example, we were recently faced with the requirements for angle of attack (AOA) of $+/-0.01$ Deg. and drag accuracy of $+/-1.0$ counts in a high lift test in the 14- by 22-Foot Subsonic Tunnel (14x22 ST). While such a requirement was unheard of for high lift testing in the past, the current HighSpeed Research (HSR) program is now requesting such accuracy requirements to meet the landing and take-off noise requirements. The relationship between high quality data and reduced cycle time cannot be overlooked. Increasing productivity, without paying attention to quality assurance, is futile. The old NASA paradigm that we always get the answers to the best of our ability is also rapidly changing. For example, if a test has a very relaxed accuracy requirement, we can estimate an approximate answer analytically and save a considerable amount of time and money! However, if a test has a very tight requirement for data accuracy, even as small as +/- 0.2 drag count, the requirement can surely be met, but it will involve a larger number of repeat runs and undoubtedly cost more time and money. Establishing the accuracy requirement up-front is now of paramount importance at the LaRC facilities. The accuracy requirements for tests at $\mathrm{LaRC}$ are almost always well founded, but not always well understood by the entire test team. Furthermore, the performance of our facilities must be understood to be able to deliver any credible level of quality in the data. Therefore, most of the cycle time reduction efforts have focused on understanding the requirements and exit criteria for each test, understanding and documenting the precision of each facility and each test in addition to increasing the productivity, and reducing the cycle time of the test process.

A considerable effort has been expended in 1998 exploring and extending the use of Modern Design of Experiments in wind tunnel testing, where one strives to define up front the minimum set of measurements to satisfy a clearly defined exit criteria for each test. This methodology was introduced to the aeronautical ground testing community by DeLoach (References 4-5) in 1997, which showed considerable promise of reducing test cycle time substantially. The key elements determining the data volume requirement for each test are: 1) what relationships are to be defined by the test, 2) how accurately do these relationships need to be known, and 3) what is an acceptable level of risk that neither something important is missed nor that something is predicted incorrectly. The process of experiment design then establishes the minimum set of measurements necessary to determine these relationships to the required accuracy. Preliminary data volume estimates are useful in that they reveal gross resource mismatches, such as test matrices that request much more data than necessary to define the desired relationships, or accuracy requirements that cannot possibly be met in the time available. After the successes in 1997, LaRC has undertaken a deliberate effort to explore and expand the use of formally designed experiments within the wind tunnel testing community over a broad range of configurations and Mach numbers. Since the introduction of MDOE to wind tunnel testing in 1997, eleven MDOE tests have been completed and nine more are currently in the design phase, as summarized in Table 1. So far, all tests have continued to show reductions in time and resource requirements greater than 50 percent. 


\begin{tabular}{|l|l|l|}
\hline \multicolumn{1}{|c|}{ Tests Completed } & \multicolumn{1}{c|}{ Facility } & \multicolumn{1}{c|}{ Speed range } \\
\hline Facility data system rate/dwell & NTF & N/A \\
\hline Supersonic HSR wing twist & UPWT & Supersonic \\
\hline Transonic HSR Force \& Moment & 16 TT & Transonic \\
\hline Subsonic HSR Tail Stabilizer & $14 \times 22$ & Subsonic \\
\hline X-33 Ground Effects & $14 \times 22$ & Subsonic \\
\hline Unconventional Control Surface Evaluation & TDT & Transonic \\
\hline Porous LEX Stability and Control & UPWT & Supersonic \\
\hline Balance Calibration Design & external & N/A \\
\hline Video Model Deformation Target Effects & UPWT & Supersonic \\
\hline Video Model Deformation Parametric Study & UPWT & Supersonic \\
\hline CCD/Split Plot design Comparison & external & N/A \\
\hline & \multicolumn{1}{|c|}{ Facility } & \multicolumn{1}{|c|}{ Speed range } \\
\hline High-lift Configuration Optimization & NTF & Subsonic \\
\hline Shape Metal Allow Behavior & TDT & Transonic \\
\hline Response Surface Adequacy Demonstration & NTF & Transonic \\
\hline Performance test MDOE Demonstration & NTF & Transonic \\
\hline High-lift HSR Optimization & $14 \times 22$ & Subsonic \\
\hline Navy Fighter Jet Study & NTF & Transonic \\
\hline Resource Minimal Flight Test & external & N/A \\
\hline Fuselage Lap Splice Performance & external & N/A \\
\hline MDOE/Neural-net Collaboration & AEDC/UTSI & N/A \\
\hline
\end{tabular}

Table 1: Recent Ground Testing Activity at LaRC using Modern Design of Experiment

A key principle in experimentation is that better measurement accuracy means a reduced data volume requirement. Moreover, the data volume requirement scales with measurement accuracy squared! Since accuracy requirements now are as much as 10 times higher than they were a decade ago, data volume requirements would be 100 times greater than a decade ago without a corresponding increase in measurement system accuracy. Fortunately, wind tunnel measurement system accuracy has increased over this period. However, it is now essential that the accuracy be fully understood, and that the measurement system performance be reliably and credibly predictable. The Data Quality Assurance (DQA) program in the WTE facilities is designed to address these issues. The DQA program at $\mathrm{LaRC}$ has four elements that are consistent with a National Institute of Standards and Technology (NIST) Measurement Assurance Program (MAP). First, the measurement process is defined using standard operating procedures to provide known and persistent operational definitions. Procedure control is provided by ISO 9000 certification, which is now in process at LaRC and will be complete by September of 1999 . The second key element is traceability to a national standard. The WTE DQA program provides traceability using both a primary process (standard wall and mounting system correction codes) and a hierarchy of secondary artifacts for instrumentation. The third element is to provide measurement stability, which can only be inferred from periodically repeated measurements on a stable artifact. Control charts, containing data acquired on check standard models and centerline probes, taken in short-term back-to-back repeat groups with a fixed number of observations, are used as graphical displays for assessing stability and making decisions when intervention is indicated. The charts are time series plots of the averages and ranges of the data groups, together with grand averages and 3-sigma limits. A process is in control if the data do not fall outside limits and exhibit only random variation (References 6-8). In every instance where a facility has initiated check standard testing to transition towards statistical control, large reductions in uncertainty have been achieved as assignable causes of variation are identified and removed. The status of calibration and check standard probe tests at the major facilities at LaRC is given in Table 2.

The fourth element of the WTE DQA Program is providing a methodology to scale the check standard repeatability to the customer models and test conditions. The test processes are designed so that the force and moment balance is the dominant source of variation, allowing the balance capacity to be used as the main scaling factor. The increased accuracy 


\begin{tabular}{|l|c|c|c|}
\hline Facility & Calibration & Check Std. Calibration & Next Check Std. Test \\
\hline $14 \times 22$ & $10 / 96$ & $10 / 96,7 / 97,9 / 97,1 / 98$ & $6 / 99$ \\
\hline NTF & $9 / 98$ & $3 / 98$ & $2 / 99$ \\
\hline LTPT & $9 / 98$ & $9 / 98$ & $1 / 99$ \\
\hline UPWT & $1980(' 99)$ & $\bullet$ & $2 / 99$ \\
\hline $16-F t$ & $1990(' 99)$ & $\bullet$ & $5 / 99$ \\
\hline TDT & $7 / 97,2 / 98$ & $\bullet$ & $12 / 98$ \\
\hline $0.3-m$ & 1985 & $\bullet$ & $12 / 98 *$ \\
\hline
\end{tabular}

* model for adaptive wall calibration

Table 2: Status of facility calibrations and Check Standard testing at LaRC

requirement is being addressed by these four elements, through which the uncertainty of the wind tunnel measurement system is quantified and reduced.

Wall induced interference can be a significant source of bias in wind tunnel data. Wall interference is the modification of tunnel flow conditions, model load distribution, or integrated forces and moments resulting from the presence of the tunnel boundaries. The effort to establish and apply a "gold standard" for wall corrections has been addressed this year in collaboration with NASA Ames Research Center, using the guidelines published in AGARD AG336 "Wind Tunnel Wall Corrections" (Reference 9). The methodology provides traceability to a national standard, again using a primary process rather than a secondary artifact. The process consists of standardized theoretical and analytical methods such as WICS (Reference 10) and PANCOR, (References 11-13), along with documented experimental techniques in facilities under Statistical Control.

The LaRC DQA program is focusing on establishing and extending NIST practices for data quality assurance in the Langley WTE facilities. This effort is systematically identifying the performance of the facilities and measurement systems, establishing processes that are in statistical control, and steadily addressing and reducing the leading causes of uncertainty. Within 2 years, the WTE plans to operate in a mode where LaRC can guarantee the negotiated results of each test, regardless of facility down time and other unexpected events, either using designed experiments or conducting conventional tests in facilities that are in a state of statistical control.

\section{The Wind Tunnel Test Process}

The Langley WTE has been striving to establish 'best practices' for reducing Test Cycle Time while also reducing process uncertainty. The NTF has undertaken an effort called Process Mapping throughout the facility, which involves understanding and documenting everything that is happening in the tunnel from the beginning to the end of the facility's role in the test process. The facility's process time starts the day a model comes into the facility and continues until the data goes out to the customer. The documentation and display of the process, from "who does what and when," to how long it takes to fill a nitrogen tank and other operational details, has proven to be invaluable to the operation of this facility. Process Mapping has provided an understanding of this facility sufficient to develop a process simulator. The simulator allows the workforce to identify the impact of schedule or process changes, and make informed choices regarding the operation of NTF. Figure 1 shows the results of an analysis that illustrates the strategic benefit that this increased understanding of the process through mapping and simulation can have on operational decisions. This mode of operation is well established in NTF, is well under development for the 8-Foot High Temperature Tunnel, and is being deployed in the rest of the WTE.

The potential for an order of magnitude reduction in test cycle time has been illustrated by a particular set of tests in the 16-Foot Transonic Tunnel (16'TT). There have been two entries this year for a test at the 16'TT where the model has been installed, a series of measurements made and the model removed in just one day. The model for this test has been selected as the check standard model for the $16^{\prime} \mathrm{TT}$ and has been 
taken out of service to be used only for this purpose. This check standard calibration test is similar to portions of a typical HSR test plan, where a standard configuration is run before the test, providing baseline forces and moments for each HSR test. All of the elements that are part of a standard wind tunnel test, including model build up, the model installation process, various calibrations, test operations, configuration changes and removal of the model, are optimized. A considerable amount of preparation must be done and several spare items must be made available in order to accomplish these tests in one day. One key element of a designed experiment was exercised during this test, understanding clearly when the exit criteria were met, which required a welldefined set of test objectives.

The test cycle time durations from these tests are shown in Figure 2. Somewhat surprisingly, the percent of wind-on time is greater during this oneday test than is normal for tests in the 16'TT. One would expect that with such a short run schedule, the time required to get into and out of the test section would reduce the percent wind-on time for the one day test. The increase in percent wind-on time is due to the fact that there is no wasted effort getting into and out of tunnel, and there are no unexpected developments in the well-rehearsed process.

\section{The Model Design and Fabrication Process}

In a continuing effort to reduce wind tunnel test cycle time at LaRC, a test cycle time reduction team was formed in 1998 in an effort to characterize the entire test cycle time. At LaRC, the wind tunnel test cycle time is defined as the time between the delivery of loft lines to the model designer and the delivery of test data to the customer. This process includes model design, model fabrication, model build-up, model installation into the tunnel, the wind tunnel test, and any preliminary data analysis required to verify the test data. Several previous efforts, and much anecdotal evidence, suggest that the model design and fabrication process is by far the largest contributor to the test cycle. The data collected this year and presented in Figure 3 clarify these notions. These data represent a summary of 59 of the most recent model requests in the model design group at LaRC. Figure 3 shows the average, minimum, and maximum time for each phase of the test cycle, indicating that the model fabrication time is by far the leading contributor to the test cycle time.

The Model Design and Fabrication groups are making use of advanced technologies now available in the Fabrication Division such as Stereo Lithography and various forms of model casting to reduce the test cycle time. These processes have been used for configuration screening tests on several Access to Space Programs such as the X-33, X-34, and the $\mathrm{X}-38$, and now and are being used for more complicated models. The group is working with fabrication equipment suppliers and using third party fabrication service providers where possible, and inventing state of the art technology as needed (Reference 10) to supplement current capability.

Coordinating the model design and fabrication schedules with the wind tunnel test dates has at times been challenging over the last few years. For example, several NASA programs have requested major model fabrication efforts nearly simultaneously, and there have been times when there are not enough qualified model fabricators with adequate Numerically Controlled Machining capability within the United States and Canada to handle the workload in the timeframes requested. In spite of this difficulty, wind tunnel tests are often scheduled independently, due to the difficulty in obtaining tunnel time. As is common in many industrial environments, the workload is well described as "Feast or Famine."

The model design process and the wind tunnel test process have been traditionally separated at LaRC since the responsibility for the two processes have resided under different line organizations. The difficulty connecting the processes has been exacerbated to some degree by completely independent management chains. As a "virtual organization," the Langley WTE has been very successful working across different line organizations at the Center. The WTE is governed by a team of managers from all areas of the center that have responsibility for some part of the test process. The group meets weekly to plan the activity of the enterprise and ensure cross-organizational communication.

The cycle time reduction team has revealed several less-than-optimum steps in the flow of work through the design process. For example, a model design is initiated with a model design request form that often requires the requestor to make several stops for signatures before being able to have a substantive technical conversation regarding model design. The cycle time reduction team continues to suggest ways for reducing and simplifying the model fabrication process.

\section{Facility Upgrades at LaRC}

In 1998, a major renovation was completed at the NTF to improve the facility productivity. This renovation was designed to increase tunnel operational readiness, reduce system delays due to Liquid Nitrogen $\left(\mathrm{LN}_{2}\right)$ and power distribution limitations and increase tunnel on-point test efficiency. The new drive system, shown in Figure 4, features a state of the art control system for increased reliability and increased shaft speed ramp rates. Figure 5 shows the new 3000 Ton $\mathrm{LN}_{2}$ storage tank which provides additional on-site $\mathrm{LN}_{2}$ supply 
sufficient for most test plans and reduces delays due to limited $\mathrm{LN}_{2}$ production and transfer rates. Other facility enhancements included a new Mach number measurement system, a new Mach number disturbance management system, automated test sequencing, and new alpha/beta controls. A key enhancement is the Automated Test Sequencing capability that allows the execution of a series of test conditions automatically. The system is an integration of several systems (Mach number setpoint and Mach number disturbances, control Alpha and Beta, as well as other systems) that allow automatic sequencing from drive start, through data acquisition to drive stop. These upgrades decrease off-setpoint time, reducing $\mathrm{LN}_{2}$ consumption and increasing the polars per hour capability by nearly a factor of two. In addition to the NTF facility upgrades, both the $14 \times 22$ ST and the Unitary Plan Wind Tunnel (UPWT) are now in the process of productivity related upgrades as well.

\section{Technology Investments}

The distribution of time spent on various activities in the wind tunnel test process is shown in Figure 6. Examination of this distribution of time shows that nearly half of the activity at a facility is spent in model build up or configuration changes and the other half is spent on tunnel operations, either running or getting the tunnel ready to run. Additional cycle time reductions have occurred due to improvements made, not only in running the tunnel, but in getting and keeping the tunnel ready to run. The WTE has invested in several key technologies that have shortened the time in model build up or in configuration changes. For example, the time for curing cryogenic model fill material is down significantly from 24 hours to just a few minutes. Quick disconnects are used in a cryogenic environment where they have not been successful before. Figure 7 shows an automated sting loading device that has been introduced at NTF this year. The process of putting check loads on the model for sting bending calibrations has been largely automated, reducing the process from days to hours.

The instrumentation group has contributed several general technology developments that either improve data quality or reduce cycle time (or both). Technology developments include the Angle Measurement System (AMS) shown in Figure 8. The AMS reduces the time for model mounting and calibration procedures by 20 percent and increases the data quality by an order of magnitude. The introduction of cryogenic electronically scanned pressure instrumentation greatly reduces calibration time while increasing accuracy of cryogenic pressure testing. Instrumentation is also being developed, shown in Figure 9, that provides on-board correction to sting whip, which is another source of AOA uncertainty. A Video Model Deformation (VMD) system (References 15-16), shown in Figure 10, has been developed here and deployed throughout the Agency, providing real time measurements of wing twist during testing. These two developments address sources of error that add up to an error in AOA (both of the model and of the local wing section) far greater than the 0.01 degree often requested by the customer.

\section{"Virtual Presence" and Internet Tools}

The information technology now in place at several facilities allows most of the customer test team to remain back in their home offices while collaborating on tests at LaRC. The Virtual Facilities effort, pioneered by Schwartz (Reference 17), provides a three-dimensional computer model of a wind tunnel testing environment. Simulated testing environments have been generated for the LaRC 14x22 ST, UPWT, and 30x60 Foot Tunnels as well as the NASA Ames 12-Foot facility. The capability enhances planning for complex experiments requiring optical access or large instrumentation systems. Figure 11 illustrates its use in a recent $14 \times 22$ ST test involving an infrared transition detection system, where it allowed a rapid tunnel entry and smoother facility operation during a very complicated test. Internet tools provide information exchange during all phases of the test process. The internet tools are a combination of software tools known as "Electronic Logbooks", "TPMS", “ADAPT" developed at LaRC and "DARWIN" developed at Ames Research Center. The internet tools provide improved pre-test, within-test, and post-test communication and logistics. The enhanced communication helps avoid problems, or anticipate problems, allowing rapid and timely solutions. The tools also allow a broader technical base to evaluate test results. A virtual presence for the entire test team is being deployed so that eventually, when models are tested for only a few hours, one does not need to fly several thousand miles to participate in the test.

\section{$\underline{\text { Global Measurement Processes }}$}

In 1998, significant progress has been made implementing global measurement processes using Pressure Sensitive and Temperature Sensitive Paints (PSP and TSP). PSP and TSP technology have been around for over 10 years, yet until recently, most tests involving PSP or TSP have been attempts to demonstrate or evaluate the technology. It is no longer a question of whether or not these tests can be done, but a matter of implementation of the technique. This year there have been eleven test requests for the use of PSP systems at WTE facilities. The focus at LaRC is now on solving roadblocks to standard implementation, which include developing 
optical access into the tunnels, ensuring camera and data system availability when needed, as well as providing a definitive evaluation of the influence of the coatings on the behavior of the test article. Such an evaluation has been carried out on the influence of fiducial markers on a model for a VMD test in the UPWT, with an unambiguous indication of a drag increase of 0.3 counts! The first transonic pressure sensitive paint measurements under cryogenic flow conditions were conducted this fall in the 0.3-Meter Transonic Cryogenic Tunnel. Tests of the cryogenic PSP system in the NTF are scheduled this year.

A global measurement technique pioneered by Flemming (Reference 18) for measuring of model deformation called Projection Moiré Interferometry (PMI) has been used very successfully at the $14 \times 22$ ST to measure rotor blade deformation of a rotorcraft under simulated forward flight. The PMI system, shown in Figure 12, is a non-intrusive, full field diagnostic technique capable of measuring large structural deformations. The current instrument capabilities are sub-millimeter deformation measurement resolution, demonstrated in the $14 \times 22$ ST to be better than $0.75 \mathrm{~mm}$ with a spatial resolution of $1-2 \mathrm{~mm} / \mathrm{pixel}$. The method, when combined with "point" measurements such as VDM and Optitrak, is analogous to the global pressure measurement of PSP used together with discrete pressure taps. The result is a highly complimentary and useful system.

\section{Next Steps}

Several new and exciting developments are underway that should revolutionize the way wind tunnel testing is done over the next 10 years. The focus of much of the wind tunnel testing at LaRC is now shifting towards understanding the underlying physical phenomena associated with a class of design problems in order to advance the aeronautical sciences. For example, it is desirable to understand which flowfield phenomena in a shear layer are responsible for the acoustic spectrum associated with airframe noise or the jet exhaust acoustic fields. Another example is the optimization of a high-lift system design tool, which accommodates the threedimensional compressible boundary layers as well as boundary layer transition prediction. Progress in testing in such areas will require new and advanced instrumentation and test techniques that can discern detailed flowfield information on advanced configurations without altering the measured field. Advances in optical methods are being sponsored by the WTE re-investment programs that have potential to benefit these areas. Examples include:

- A new point velocity-temperature-pressure measurement technique is being developed, somewhat similar to Laser Doppler Velocimetry that does not require any seed material added to the flow.
- MEMS technology representing a whole new arena of measurement capabilities, such as local measurement of steady and unsteady pressure and shear stress.

- Simultaneous transition/shock-position and pressure field measurement using luminescent coatings.

Our vision of the future of wind tunnel testing is one where the customer interacts with the wind tunnel service providers over the internet, supplying configuration geometry and questions to be answered, the model is then fabricated overnight and is tested within a few days of the request. The customer has complete interactive involvement with every aspect of the test process, essentially driving the experiment as the desired relationships are developed to acceptable levels of resolution and confidence.

\section{$\underline{\text { References }}$}

${ }^{1}$ Putnam, Lawrence E.: "Re-engineering Wind Tunnel Testing at NASA Langley Research Center," Symposium of the International Test and Evaluation Association, Huntsville, AL, October 2-5, 1995.

${ }^{2}$ Putnam, Lawrence E.: "Wind Tunnel Productivity Status and Improvement Activities at NASA Langley Research Center," AIAA Paper 96-2260, 1996.

${ }^{3}$ Kegelman, Jerome T.: “Accelerating Ground-Test Cycle Time; The Six-Minute Model Change and Other Visions for the 21st Century," AIAA Paper 980142, 1998.

${ }^{4}$ DeLoach, Richard: "Tailoring wind tunnel data volume requirements through the formal design of experiments," AIAA Paper 98-2884, 1998.

${ }^{5}$ DeLoach, Richard: "Applications of Modern Experiment Design to Wind Tunnel Testing at NASA Langley Research Center," AIAA Paper 98-0713, 1998.

${ }^{6}$ Hemsch, Michael J.: "Development and Status of Data Quality Assurance Program at NASA Langley Research Center-Toward National Standards," AIAA Paper 96-2214, June 17-20, 1996.

${ }^{7}$ Wheeler, Donald J.: “Advanced Topics in Statistical Control: The Power of Shewhart's Charts," SPC Press, 1995.

${ }^{8}$ Eisenhart, Churchill: "Realistic Evaluation of the Precision and Accuracy of Instrument Calibration Systems," J. Res. NBS - C. Eng. and Inst., Vol. 67C, No. 2, Apr.-Jun. 1963. 
${ }^{9}$ AGARD-AG-336 "Wind Tunnel Wall Corrections," Ewald. B. F. R. (Editor), Canada Communication Group, Inc., 1998.

${ }^{10}$ US Patent No. 5,266,252, "Ceramic Slip Casting Technique"

${ }^{11}$ Ulbrich, Norbert: The Real-Time Interference Correction System of the NASA Ames 12-Foot Pressure Wind Tunnel. NASA CR-1998-208537. July 1998.

${ }^{12}$ Kemp, William B., Jr.: A Panel Method Procedure for Interference Assessment in Slotted-Wall Wind Tunnels. AIAA Paper 88-2537, June 1988.

${ }^{13}$ Kemp, William B., Jr.: User's Guide to PANCOR: A Panel Method Program for Interference Assessment in Slotted-Wall Wind Tunnels. NASA CR-187479, December 1990.

${ }^{14}$ Kemp, William B. Kemp, Jr.: Description and Evaluation of an Interference Assessment Method for
Slotted-Wall Wind Tunnel. NASA CR-4352, April 1991.

${ }^{15}$ Burner, A. W. and Martinson, S. D.: "Automated wing twist and bending measurements under aerodynamic load," AIAA Paper 96-2253 (A9636664), 1996.

${ }^{16}$ Bell, James H. and Burner, Alpheus W.: "Data fusion in wind tunnel testing - Combined pressure paint and model deformation measurements," AIAA Paper 98-2500 (A98-32698), 1998.

${ }^{17}$ Schwartz, Richard J.: "Virtual Facilities - A tool for wind tunnel instrumentation," AIAA Paper 982720 (A98-32744), 1998.

${ }^{18}$ Fleming, G. A., and Gorton, S. A.: "Measurement of Rotorcraft Blade Deformation using Projection Moire Interferometry," Third International Conference on Vibration Measurements by Laser Techniques, Ancona, Italy. June 16-19, 1998. Proc. SPIE, vol. 3411, pp. 514-527.

\section{Figures}

\section{Ouestion}

Test Project Planning

hat is the impact of resequencing $\mathrm{X}-33$ test runs in order to obtain a more efficient test temperature profile in cryo mode?

Process Improvement

Multi-test Planning

Operational Strategy
What is the potential impact of having the redesigned access housing available during a semi-span test similar to the 777 project?

Are 5 days enough to adequately recharge the tanks to allow the start of the test following the centerline pipe test (high LN2 use test)?

Is it more efficient to have Praxair transfer LN2 to the supply tank or the run tank?

\section{Results}

Alternate test temperature profile: cost savings of $\$ 320 \mathrm{~K}$ and project reduced by 3.5 days. (Example: $120^{\circ}, 0^{\circ},-250^{\circ}$, Model Change, $-250^{\circ}, 0^{\circ}, 120^{\circ}$ )

Housing redesign eliminates the need for gas exchanges, warmups \& cooldowns for model changes. 777 Test (23 model changes): cost savings of $\$ 1.7 \mathrm{M}$ and time savings of $35+$ shifts.

Able to recharge from $10 \%$ to $80 \%$ of onsite capacity within 5 days. O.K. to start next test project.

Proposal: develop pumping logic to always receive LN2. First pump to run tank (short term throughput) then switch over to supply tank (long term throughput).

Figure 1: NTF Simulator Output as a Tool for Decision Making 


\begin{tabular}{|l|l|l|l|l|}
\hline \multicolumn{1}{|c|}{ Test } & Test Duration & \multicolumn{1}{|c|}{$\begin{array}{c}\text { Model } \\
\text { Installation }\end{array}$} & $\begin{array}{c}\text { Model } \\
\text { Removal }\end{array}$ & \multicolumn{1}{c|}{$\begin{array}{c}\text { \% of Total } \\
\text { Occupancy Hours } \\
\text { Wind-on }\end{array}$} \\
\hline HSR tests* & $\begin{array}{l}\text { 3 weeks } \\
\text { (30 shifts) long }\end{array}$ & $\begin{array}{l}\text { Typically 2 or 3 } \\
\text { shifts }\end{array}$ & $\begin{array}{l}\text { At least 1 } \\
\text { shift }\end{array}$ & $24 \%$ \\
\hline One Day tests** & $\begin{array}{l}1 \text { day } \\
(2 \text { shifts) long }\end{array}$ & Typically 2 hours & $\begin{array}{l}\text { At least 3 } \\
\text { hours }\end{array}$ & $36 \%$ \\
\hline
\end{tabular}

*Based on the last five years

**Based on two tests

Figure 2: Summary of process times for testing in $16^{\prime} \mathrm{TT}$

\section{Minimum, Average, and Maximum Elapsed Time \\ for each step in the Test Process \\ (Data for tests over last 3 years)}

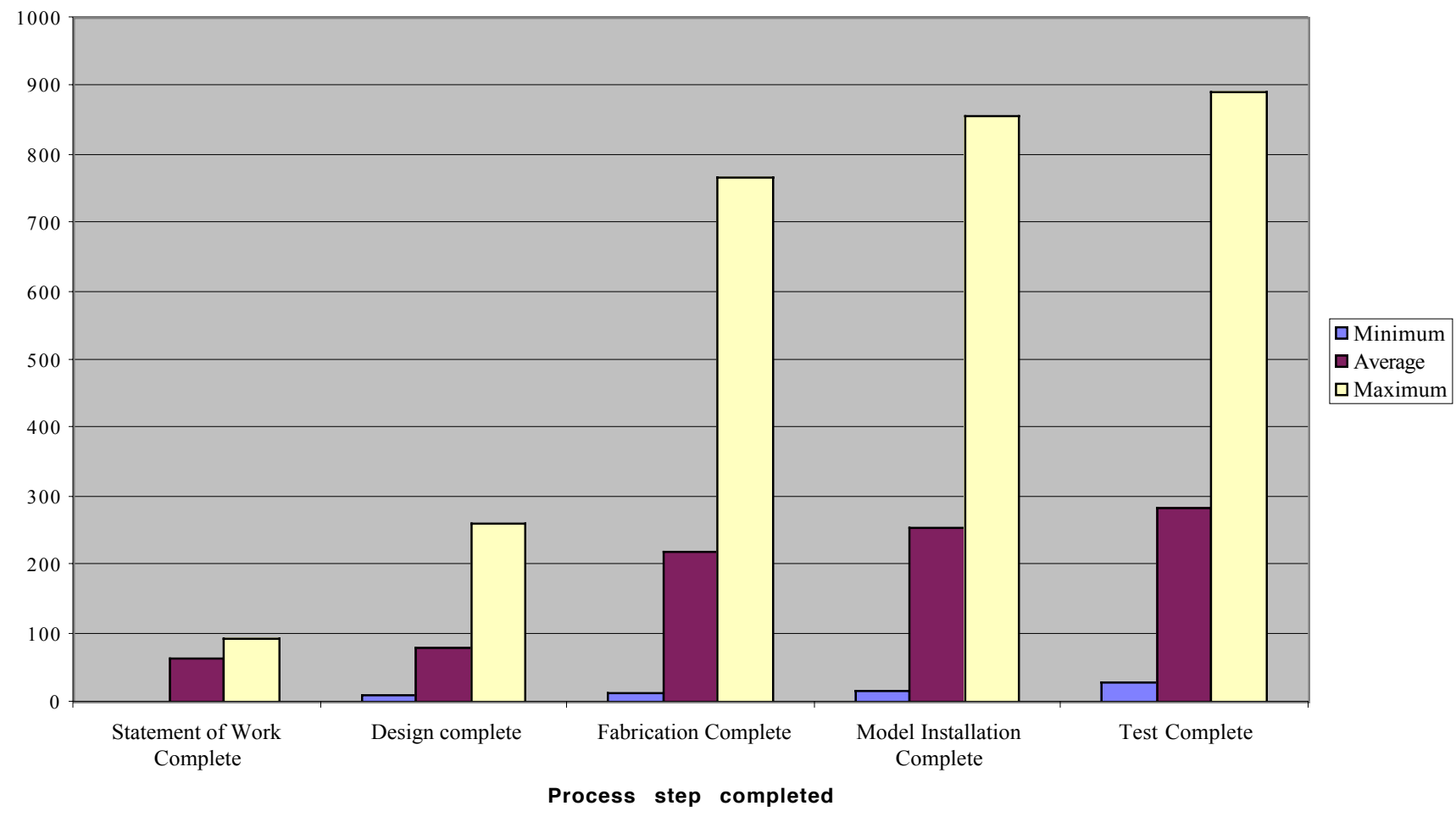

Figure 3: Duration in days for cumulative completion of elements of the test process 


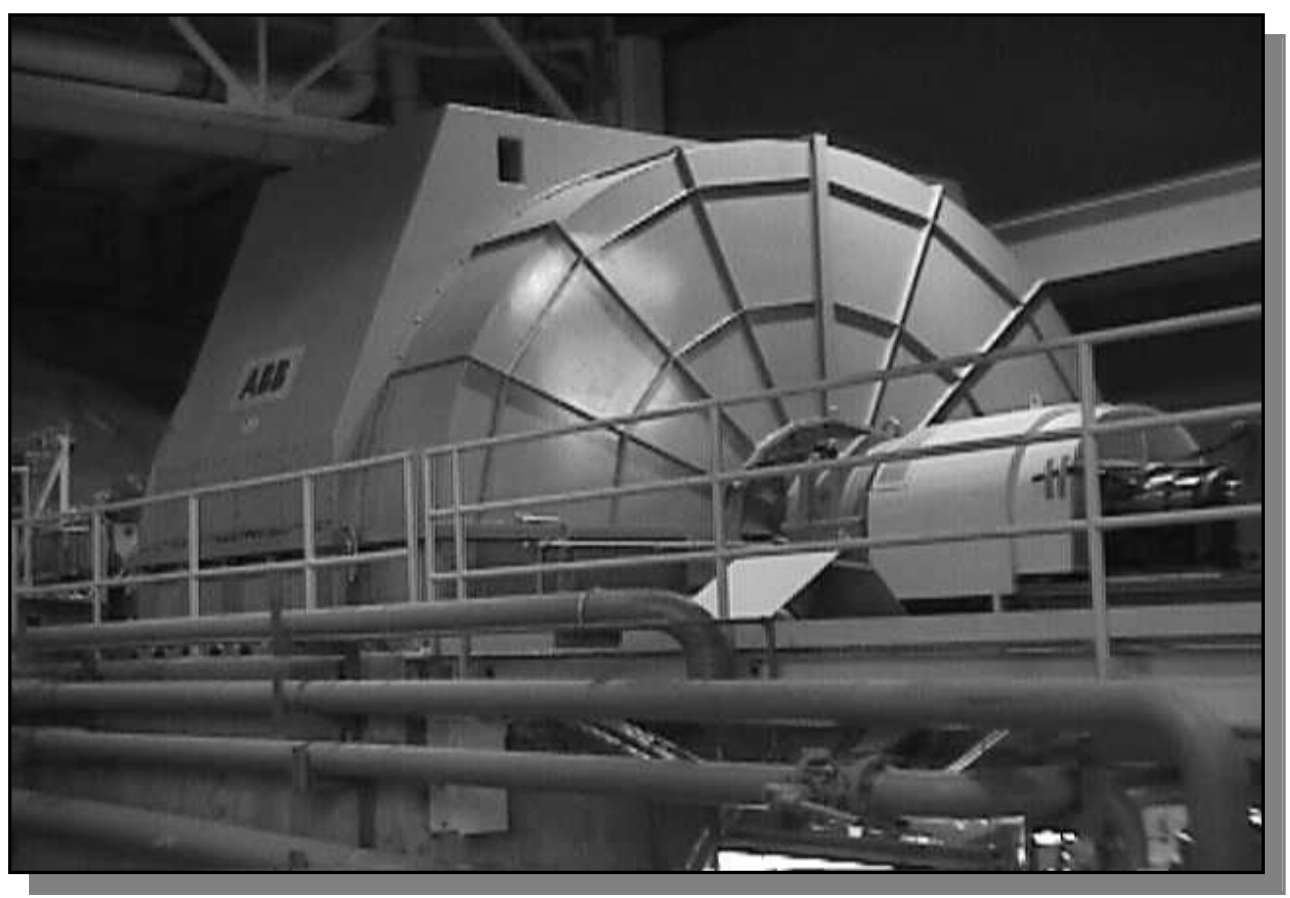

Figure 4: The new $100 \mathrm{MW}$ Drive motor for the NTF

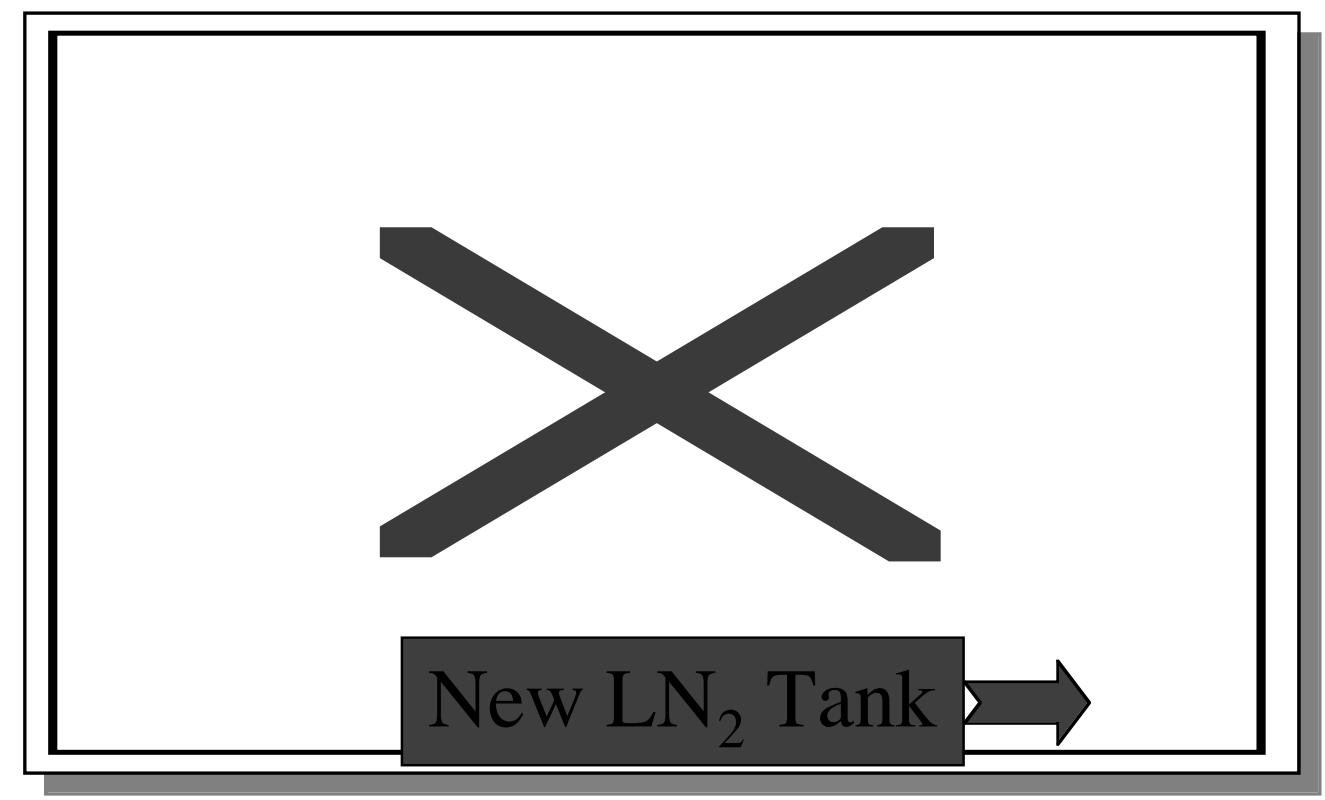

Figure 5: The new LN2 Storage tank for the NTF 


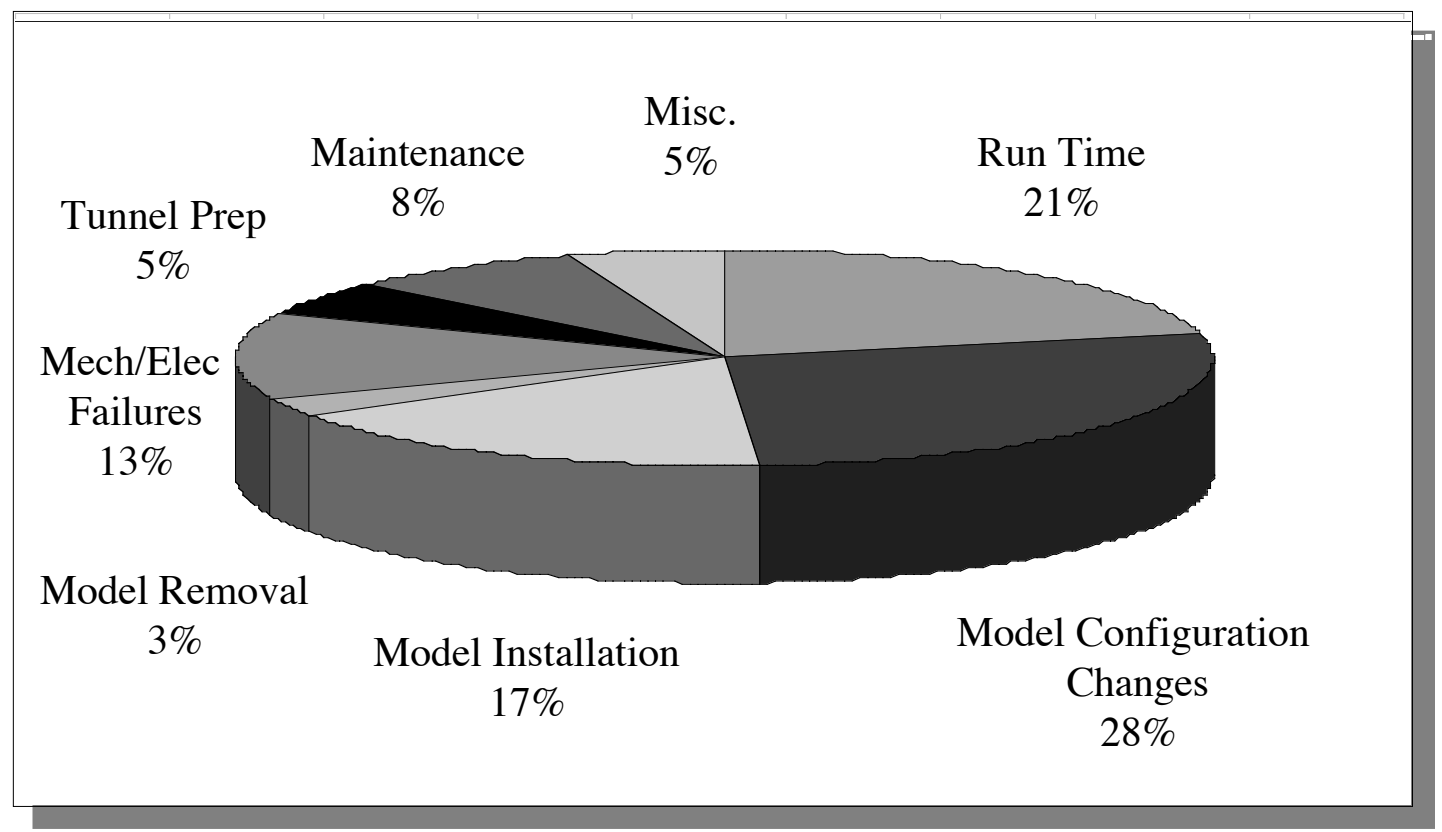

Figure 6: The distribution of effort in the facility wind tunnel processes

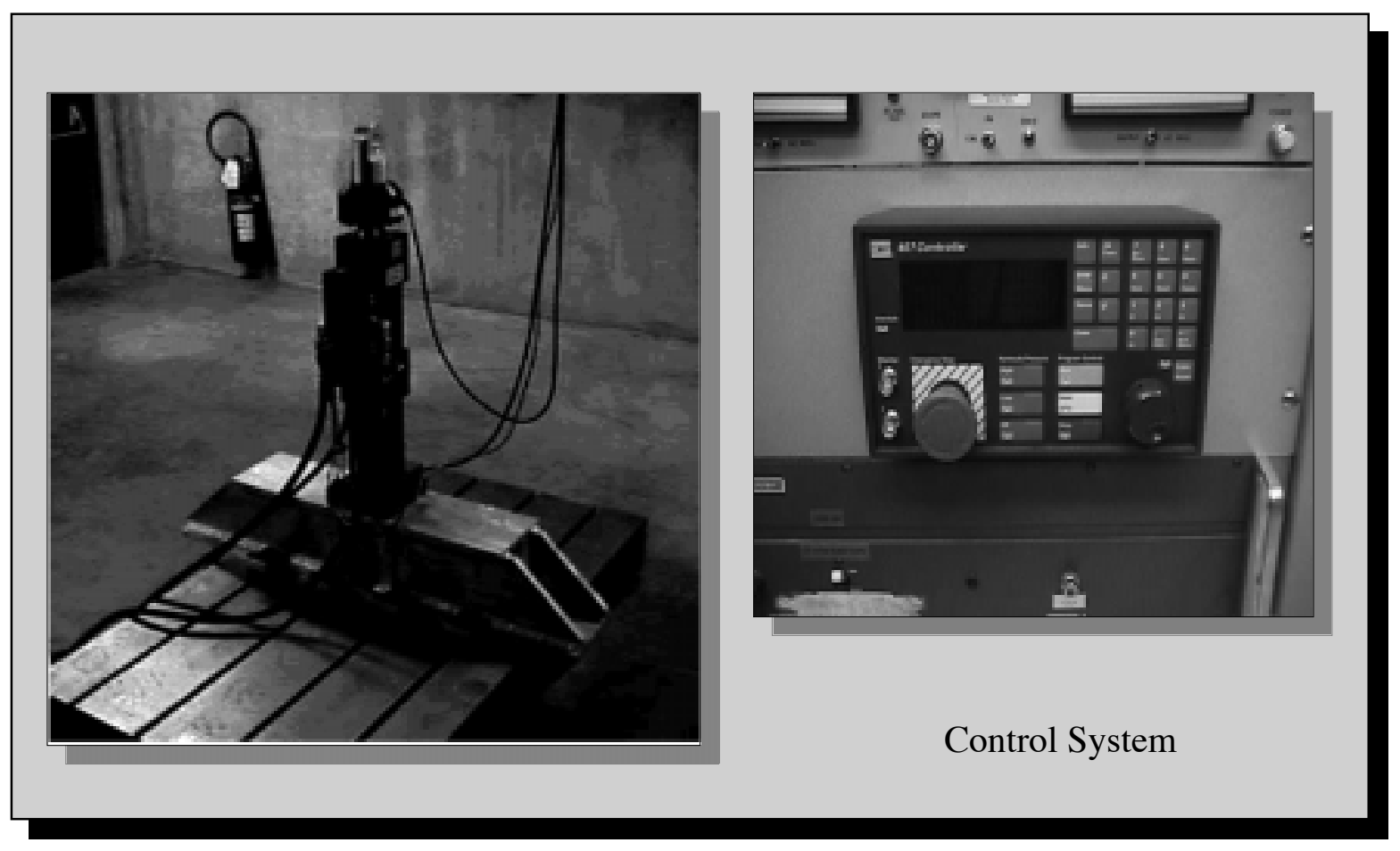

Figure 7: The automatic hydraulic loading system for NTF 


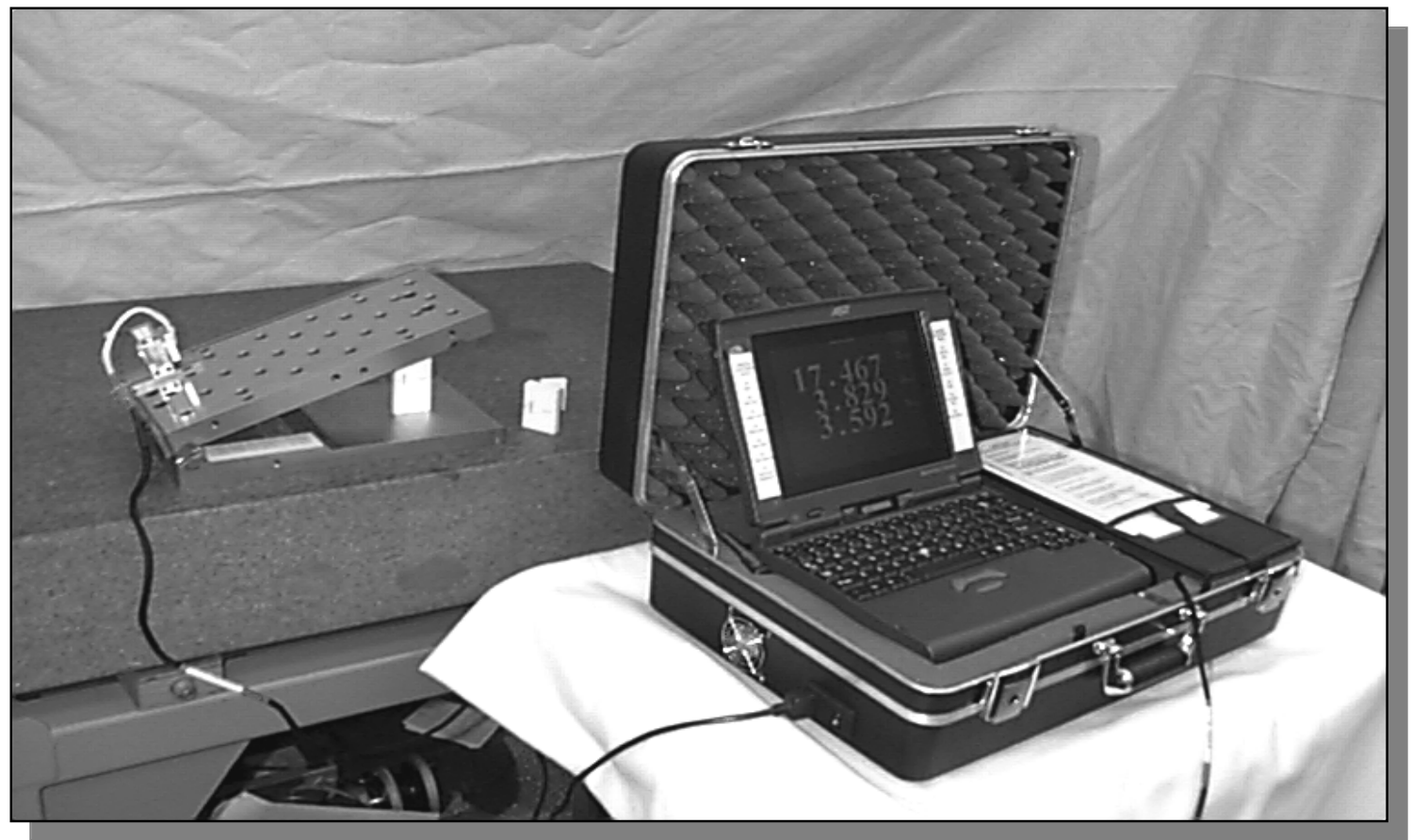

Figure 8: The Angle Measurement system shown with calibration sign block

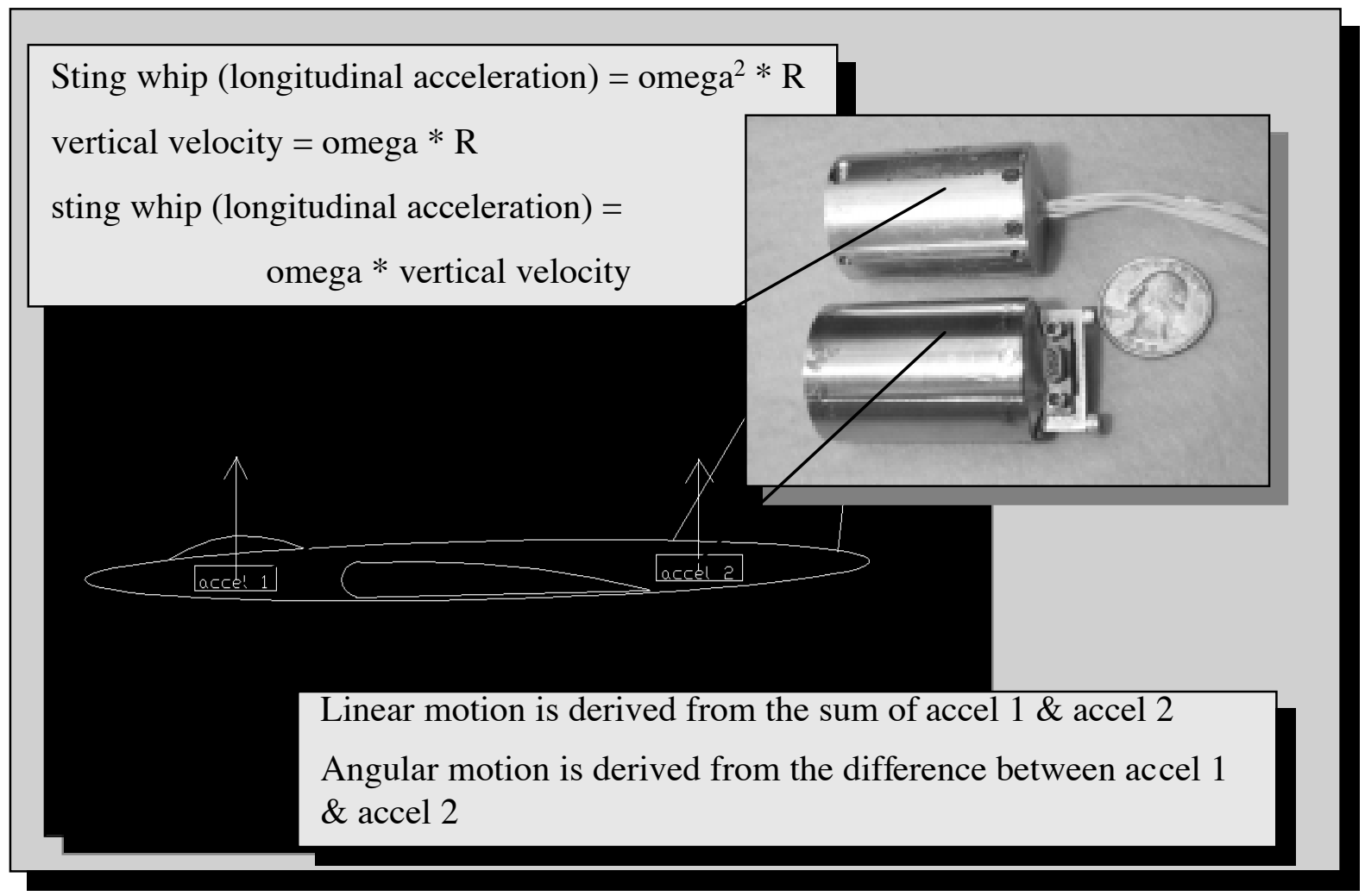

Figure 9: Sting whip accelerometers for correction due to motion in vertical plane 


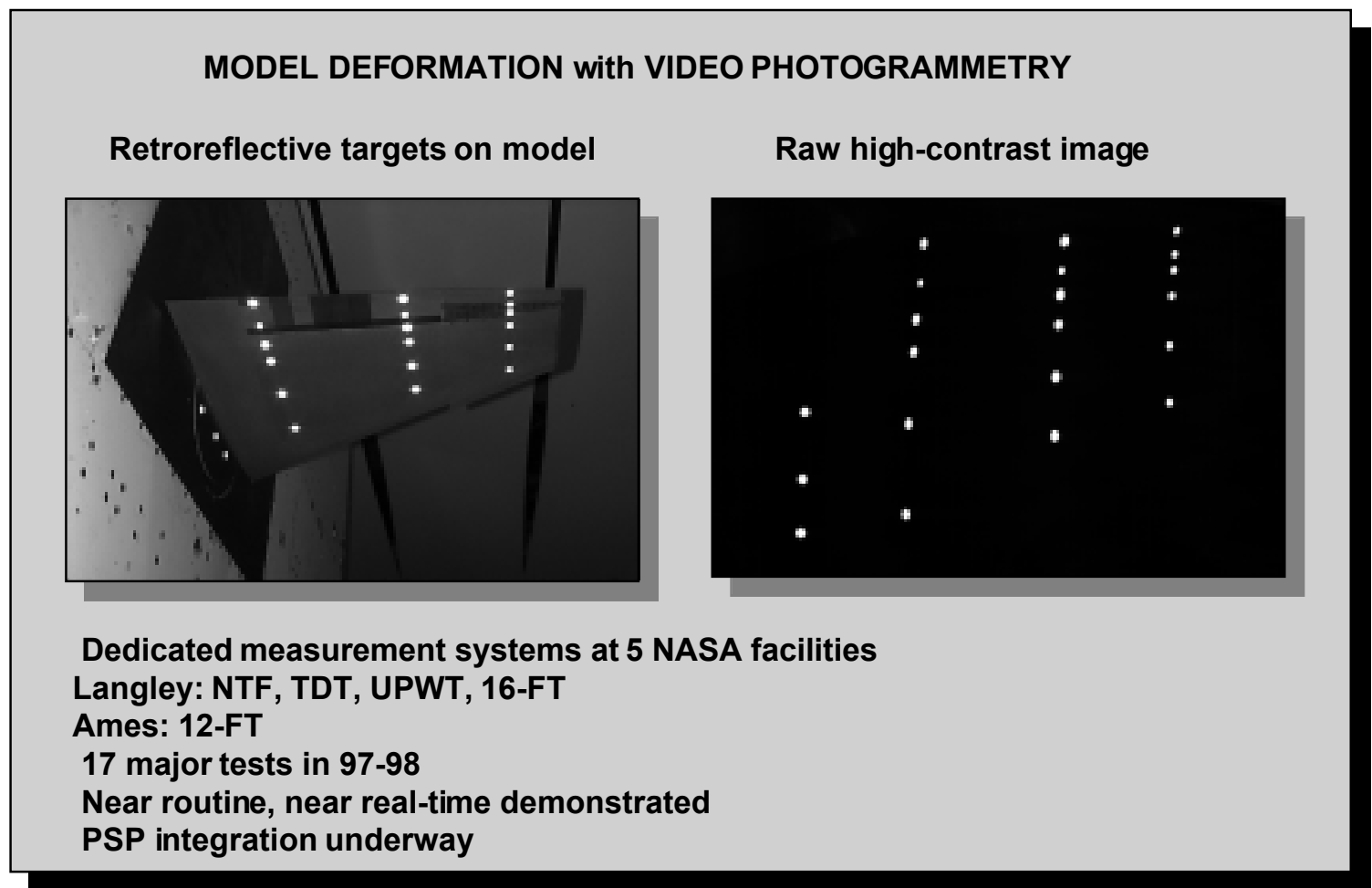

Figure 10: Model deformation and video photogrammetry images from a test in TDT

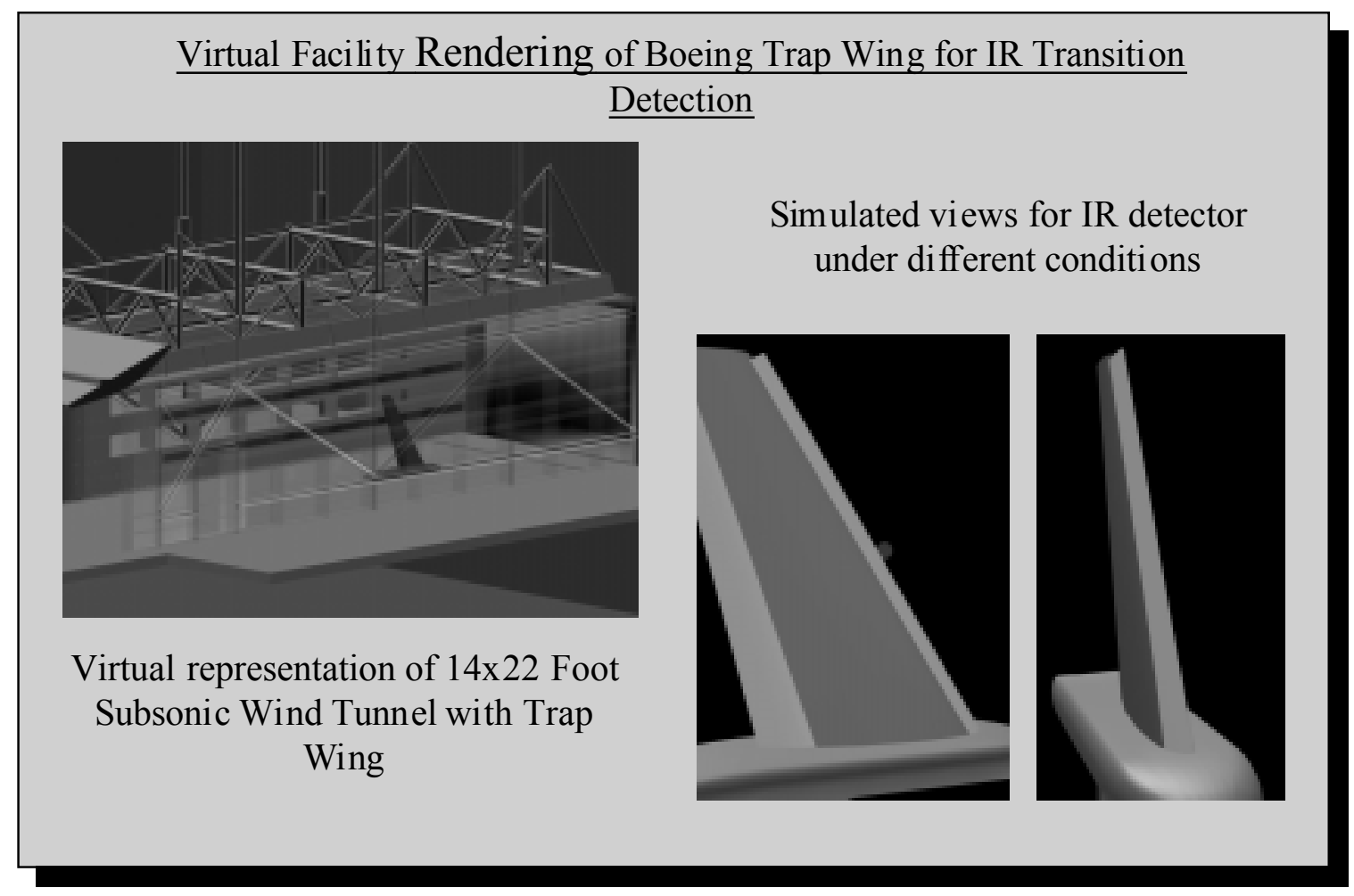

Figure 11: Simulation of a Flow Physics Test in the 14x22 ST 